Editorial

\title{
Progressive Resistance Training as Complementary Therapy for Polycystic Ovarian Syndrome
}

\section{Treinamento de Resistência Progressiva como Terapia Complementar Para Síndrome de Ovário Policístico}

\author{
Gislaine Satyko Kogure ${ }^{1}$ Rosana Maria dos Reis ${ }^{1}$ \\ 1 Department of Gynecology and Obstetrics, Faculdade de Medicina \\ de Ribeirão Preto, Universidade de São Paulo, Ribeirão Preto, \\ SP, Brazil
}

Rev Bras Ginecol Obstet 2017;39:255-257.

Polycystic ovarian syndrome (PCOS) significantly impacts women, since the broad spectrum of clinical manifestations associated with it are significant and include reproductive dysfunction, menstrual irregularities, and an increased risk of infertility. However, the consequences of PCOS go beyond the reproductive axis, with psychological and social impairments, including stress, depression, anxiety, and sexual dissatisfaction. ${ }^{1}$ There is also a high prevalence of dyslipidemia, hyperinsulinemia, obesity, hypertension, and glucose intolerance, which are risk factors that predispose women to cardiovascular disease (CVD) and diabetes mellitus type 2 (DM2). ${ }^{2}$ Therefore, PCOS assumes aspects of a chronic disease, as these factors extend throughout life. If not prevented and treated, they can lead to increased morbidity and mortality. ${ }^{3}$ The etiology of PCOS has not been fully elucidated, but it is known to be linked to excess androgens. ${ }^{4,5}$ Insulin resistance (IR) is a common feature of PCOS, ${ }^{6}$ and although it is not considered a diagnostic criterion, it is a key factor in the syndrome's etiology and evolution. ${ }^{7}$

In 2008, the European Society of Human Reproduction and Embryology (ESHRE) and the American Society for Reproductive Medicine (ASRM) published a consensus suggesting lifestyle changes as the first line of treatment for women with PCOS. ${ }^{8}$ This consensus was reinforced in 2009 by The Androgen Excess and Polycystic Ovary Syndrome Society, ${ }^{9}$ which investigated evidence of lifestyle management (dietary, exercise, or behavioral interventions) for obesity in women with PCOS. Since then, the benefits of lifestyle changes resulting from PCOS therapy have been well documented. ${ }^{10,11}$ The rationale for this non-pharmacological therapy is based on regular exercise and a healthy diet, as well as combined interventions that aim to achieve and maintain a healthy weight to minimize hormonal and reproductive complications, reduce the long-term risks of chronic diseases such as CVD and DM2, and consequently improve quality of life. In this way, weight loss has been considered the main goal of PCOS therapy in obese women.

Moderate- to high-intensity aerobic physical exercise ${ }^{12}$ has been predominantly recommended as a treatment for PCOS. ${ }^{13}$ Preliminary data from our group with an interval aerobic training protocol (exercises alternating in intensity from moderate to heavy effort with low-effort recovery periods) showed a decreased central obesity index measured by anthropometric measures and improved testosterone levels. However, other training programs, such as aerobic exercises, alone or in combination with resistance training, with or without dietary restriction, have also effectively reduced total and abdominal body fat or body fat percentile, ${ }^{12,14-16}$ leading to improved menstrual frequency and/or ovulation, ${ }^{12,17}$ reduced serum testosterone concentrations and fasting plasma glucose levels, ${ }^{12}$ and improved insulin sensitivity. ${ }^{18,19}$

More recently, a review presented evidence that progressive resistance training (PRT), or strength training, may also be beneficial for women with PCOS, promoting changes in body composition and associated factors, especially IR. ${ }^{20}$ However, this type of physical exercise has not been well explored in terms of its therapeutic purposes. Faced with the phenotypic characteristics of PCOS, we set out to perform a periodic protocol of resistance exercises in lean, overweight, and obese women with the intention of evaluating the results of this therapy. The PRT improved hyperandrogenism and the menstrual cycle, as well as the functional capacity with increased muscle strength, and resulted in changes in body
Address for correspondence DOI https://doi.org/

Rosana Maria dos Reis, PhD, MD, Department of ObGyn, Ribeirão Preto Medical School, Universidade de São Paulo, Av. Bandeirantes, 3900, 14049-900 - Ribeirão Preto, SP, Brazil (e-mail: romareis@fmrp.usp.br).
$10.1055 / \mathrm{s}-0037-1602705$ ISSN $0100-7203$
Copyright (c) 2017 by Thieme Revinter Publicações Ltda, Rio de Janeiro, Brazil

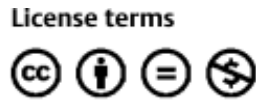


composition with increased lean muscle mass and decreased central obesity, without a reduced total weight. ${ }^{21}$ There were also improvements in quality of life and sexual function as complementary benefits. ${ }^{22,23}$

Evidence in the literature suggests that a PRT protocol associated with the practice of calisthenics (exercises that use the body's own weight as the primary tool) promoted significant changes in body composition, even with the increase of total weight and lean muscle strength in overweight and obese individuals. It also promoted improvements in several health-related domains, such as anxiety, depression, and quality of life. ${ }^{24}$ There was also a significant improvement in body composition without reductions in the total weight of lean women, regardless of the type of training when highintensity interval aerobic physical exercise and PRT were compared. ${ }^{25}$ These studies are pioneers in the evaluation of PRT alone, in women with PCOS, and attest that strength training can be an excellent and effective exercise option.

The improvement in body composition, with little or no effective change in total body weight, may be related to the concomitance of the increase in lean muscle mass and reduced body fat promoted by this type of exercise. ${ }^{26}$ The loss of fat mass is probably mediated by an increase in the basal metabolic rate that results from an increase in lean muscle mass, which is considered a metabolically active tissue that causes the body to increase its caloric expenditure. ${ }^{27,28}$ This anabolic action adds to the improved insulin sensitivity, ${ }^{27,29,30}$ since the skeletal muscles are predominantly involved in insulinmediated glucose uptake, ${ }^{31,32}$ while muscle contractile activity may stimulate the translocation of glucose transporter type 4 (GLUT4) molecules in the absence of insulin. ${ }^{33,34}$ This is a key consideration for women with PCOS, since IR is implicated in the etiology of the disease. ${ }^{6,7}$

The obesity that affects most women with $\mathrm{PCOS}^{35}$ is associated with reduced muscle strength, difficulties in postural control, and changes in the biomechanical behavior of the lower limbs, ${ }^{36}$ and may be a limiting factor for some physical activities. In particular, those physical activities with a great cyclic impact, such as walking, running, and those that require great joint amplitude are affected by obesity, since the excess weight alone puts a significant amount of stress on the joints. In addition, rapid exhaustion due to reduced physical fitness and functional capacity, even with low physical effort, contributes to the non-compliance with this type of exercise. In addition to the aforementioned benefits, as a therapy for obese women, PRT improves daily functional capacity, increases resistance to joint impact, promotes muscle strengthening, reduces the risk of injury, and favors subsequent aerobic exercises ${ }^{37}$ within the recommended levels. ${ }^{12}$

Intervention programs with aerobic training or strength training performed exclusively induce favorable adaptations in women with PCOS. Although aerobic exercises are more highly recommended, a consistent training protocol including aerobic and strength exercises, either in the same session or on alternate days, can be both efficient and capable of improving the variables of the components of physical fitness related to health, such as muscle strength, and of preventing loss of lean mass. This protocol can also improve disease-related characteristics, such as central obesity, hyperandrogenism, and insulin sensitivity.

Physical performance depends not only on the factors inherent to the suggested training program, but also on the degree of motivation for certain activities. With the proven effectiveness of the different physical training modalities, the possibility that it will provide personal satisfaction is increased, which can promote better adherence to the training program. Evidently, the positive effects of exercise may vary significantly among lifestyles as well as exercise program levels, such as intensity, frequency, and duration. ${ }^{38}$ These should be prescribed individually by a physical educator with a focus on the expectations and motivations of women with PCOS and, above all, the safety of the proposed exercises. It is believed that therapeutic orientations based on non-pharmacological therapy may favor behavioral changes and the adoption of healthy lifestyle habits for women with PCOS.

\section{References}

1 Himelein MJ, Thatcher SS. Polycystic ovary syndrome and mental health: A review. Obstet Gynecol Surv 2006;61(11):723-732

2 American Association of Clinical Endocrinologists Polycystic Ovary Syndrome Writing Committee. American Association of Clinical Endocrinologists position statement on metabolic and cardiovascular consequences of polycystic ovary syndrome. Endocr Pract 2005;11(02):126-134

3 Azziz R, Carmina E, Dewailly D, et al; Androgen Excess Society. Positions statement: criteria for defining polycystic ovary syndrome as a predominantly hyperandrogenic syndrome: an Androgen Excess Society guideline. J Clin Endocrinol Metab 2006; 91(11):4237-4245

4 Barth JH, Yasmin E, Balen AH. The diagnosis of polycystic ovary syndrome: the criteria are insufficiently robust for clinical research. Clin Endocrinol (Oxf) 2007;67(06):811-815

5 Svendsen PF, Nilas L, Nørgaard K, Madsbad S. [Polycystic ovary syndrome. New pathophysiological discoveries-therapeutic consequences]. Ugeskr Laeger 2005;167(34):3147-3151 Danish

6 Stepto NK, Cassar S, Joham AE, et al. Women with polycystic ovary syndrome have intrinsic insulin resistance on euglycaemic-hyperinsulaemic clamp. Hum Reprod 2013;28(03):777-784

7 Diamanti-Kandarakis E, Papavassiliou AG. Molecular mechanisms of insulin resistance in polycystic ovary syndrome. Trends Mol Med 2006;12(07):324-332

8 Thessaloniki ESHRE/ASRM-Sponsored PCOS Consensus Workshop Group. Consensus on infertility treatment related to polycystic ovary syndrome. Hum Reprod 2008;23(03):462-477

9 Moran LJ, Pasquali R, Teede HJ, Hoeger KM, Norman RJ. Treatment of obesity in polycystic ovary syndrome: a position statement of the Androgen Excess and Polycystic Ovary Syndrome Society. Fertil Steril 2009;92(06):1966-1982

10 Haqq L, McFarlane J, Dieberg G, Smart N. Effect of lifestyle intervention on the reproductive endocrine profile in women with polycystic ovarian syndrome: a systematic review and metaanalysis. Endocr Connect 2014;3(01):36-46

11 Moran LJ, Hutchison SK, Norman RJ, Teede HJ. Lifestyle changes in women with polycystic ovary syndrome. Cochrane Database Syst Rev 2011;(02):CD007506

12 Thomson RL, Buckley JD, Noakes M, Clifton PM, Norman RJ, Brinkworth GD. The effect of a hypocaloric diet with and without exercise training on body composition, cardiometabolic risk profile, and reproductive function in overweight and obese women with polycystic ovary syndrome. J Clin Endocrinol Metab 2008;93(09):3373-3380 
13 Teede HJ, Misso ML, Deeks AA, et al; Guideline Development Groups. Assessment and management of polycystic ovary syndrome: summary of an evidence-based guideline. Med J Aust 2011;195(06):S65-S112

14 Huber-Buchholz MM, Carey DG, Norman RJ. Restoration of reproductive potential by lifestyle modification in obese polycystic ovary syndrome: role of insulin sensitivity and luteinizing hormone. J Clin Endocrinol Metab 1999;84(04):1470-1474

15 Thomson RL, Brinkworth GD, Noakes M, Clifton PM, Norman RJ, Buckley JD. The effect of diet and exercise on markers of endothelial function in overweight and obese women with polycystic ovary syndrome. Hum Reprod 2012;27(07):2169-2176

16 Thomson RL, Buckley JD, Moran LJ, et al. Comparison of aerobic exercise capacity and muscle strength in overweight women with and without polycystic ovary syndrome. BJOG 2009;116(09): 1242-1250

17 Aubuchon M, Laughbaum N, Poetker A, Williams D, Thomas M. Supervised short-term nutrition and exercise promotes weight loss in overweight and obese patients with polycystic ovary syndrome. Fertil Steril 2009;91(4, Suppl):1336-1338

18 Harrison CL, Stepto NK, Hutchison SK, Teede HJ. The impact of intensified exercise training on insulin resistance and fitness in overweight and obese women with and without polycystic ovary syndrome. Clin Endocrinol (Oxf) 2012;76(03):351-357

19 Hutchison SK, Stepto NK, Harrison CL, Moran LJ, Strauss BJ, Teede HJ. Effects of exercise on insulin resistance and body composition in overweight and obese women with and without polycystic ovary syndrome. J Clin Endocrinol Metab 2011;96(01): E48-E56

20 Cheema BS, Vizza L, Swaraj S. Progressive resistance training in polycystic ovary syndrome: can pumping iron improve clinical outcomes? Sports Med 2014;44(09):1197-1207

21 Kogure GS, Miranda-Furtado CL, Silva RC, et al. Resistance exercise impacts lean muscle mass in women with polycystic ovary syndrome. Med Sci Sports Exerc 2016;48(04):589-598

22 Lara LA, Ramos FK, Kogure GS, et al. Impact of physical resistance training on the sexual function of women with polycystic ovary syndrome. J Sex Med 2015;12(07):1584-1590

23 Ramos FK, Lara LA, Kogure GS, et al. Quality of life in women with polycystic ovary syndrome after a program of resistance exercise training. Rev Bras Ginecol Obstet 2016;38(07):340-347

24 Vizza L, Smith CA, Swaraj S, Agho K, Cheema BS. The feasibility of progressive resistance training in women with polycystic ovary syndrome: a pilot randomized controlled trial. BMC Sports Sci Med Rehabil 2016;8:14
25 Almenning I, Rieber-Mohn A, Lundgren KM, Shetelig Løvvik T, Garnæs KK, Moholdt T. Effects of high intensity interval training and strength training on metabolic, cardiovascular and hormonal outcomes in women with polycystic ovary syndrome: a pilot study. PLoS One 2015;10(09):e0138793

26 Hunter GR, Bryan DR, Wetzstein CJ, Zuckerman PA, Bamman MM. Resistance training and intra-abdominal adipose tissue in older men and women. Med Sci Sports Exerc 2002;34(06):1023-1028

27 Tresierras MA, Balady GJ. Resistance training in the treatment of diabetes and obesity: mechanisms and outcomes. J Cardiopulm Rehabil Prev 2009;29(02):67-75

28 Strasser B, Siebert U, Schobersberger W. Resistance training in the treatment of the metabolic syndrome: a systematic review and meta-analysis of the effect of resistance training on metabolic clustering in patients with abnormal glucose metabolism. Sports Med 2010;40(05):397-415

29 Holten MK, Zacho M, Gaster M, Juel C, Wojtaszewski JF, Dela F. Strength training increases insulin-mediated glucose uptake, GLUT4 content, and insulin signaling in skeletal muscle in patients with type 2 diabetes. Diabetes 2004;53(02):294-305

30 Strasser B, Schobersberger W. Evidence for resistance training as a treatment therapy in obesity. J Obes 2011;2011:482564

31 DeFronzo RA, Jacot E, Jequier E, Maeder E, Wahren J, Felber JP. The effect of insulin on the disposal of intravenous glucose. Results from indirect calorimetry and hepatic and femoral venous catheterization. Diabetes 1981;30(12):1000-1007

32 Smith AG, Muscat GE. Skeletal muscle and nuclear hormone receptors: implications for cardiovascular and metabolic disease. Int J Biochem Cell Biol 2005;37(10):2047-2063

33 Hayashi T, Hirshman MF, Fujii N, Habinowski SA, Witters LA, Goodyear LJ. Metabolic stress and altered glucose transport: activation of AMP-activated protein kinase as a unifying coupling mechanism. Diabetes 2000;49(04):527-531

34 Goodyear LJ, Kahn BB. Exercise, glucose transport, and insulin sensitivity. Annu Rev Med 1998;49:235-261

35 Vrbikova J, Hainer V. Obesity and polycystic ovary syndrome. Obes Facts 2009;2(01):26-35

36 Wearing SC, Hennig EM, Byrne NM, Steele JR, Hills AP. The biomechanics of restricted movement in adult obesity. Obes Rev 2006;7(01):13-24

37 Ramos AT. Atividade física: diabéticos, gestantes, 3aidade, crianças, obesos. São Paulo: Sprint; 1996

38 Marx JO, Ratamess NA, Nindl BC, et al. Low-volume circuit versus high-volume periodized resistance training in women. Med Sci Sports Exerc 2001;33(04):635-643 